\title{
Behavior in reverse: reasons for return migration
}

\author{
ODED STARK* \\ University of Bonn, Bonn, Germany and University of Warsaw, Warsaw, Poland
}

\begin{abstract}
Received research shows numerous motives for migration, but fewer reasons for return migration. This paper aims to correct this imbalance. Twelve reasons for return migration are presented and discussed briefly. The reasons listed are derived from research on migration conducted by the author in the course of the past three and a half decades. The purpose of the paper is to pull together insights gained from that research so as to formulate a base for future inquiry, both analytical and empirical. In addition, just as research on motives for migration can help to establish the reasons for return migration, research on the latter can help to deepen understanding of the former. Moreover, in a great many circumstances and for a variety of reasons, countries that host migrants may want them to leave. In such circumstances, enacting policies that align with motives for return migration will be more efficient than devising measures that are independent of these motives.
\end{abstract}

Submitted 31 December 2017; revised 26 April 2018; accepted 17 May 2018

\section{Introduction}

In 2016, German Chancellor Angela Merkel expressed the view that what Germany offered to more than one million refugees and migrants in 2015 is "a temporary residential status, and we expect that once there is peace in Syria again, once IS has been defeated in Iraq, you will go back to your home country with the knowledge that you have gained." She noted that "70 percent of refugees that fled to Germany from the war in the former Yugoslavia in the 1990s have returned to their home countries." 1 There is abundant research on motives for migration, but much less has been written on reasons for return migration. The purpose of this paper is to help to

\footnotetext{
* Correspondence to: ZEF, University of Bonn, Walter-Flex-Strasse 3, D-53113 Bonn, Germany. Email: ostark@uni-bonn.de

1 http://www.reuters.com/article/us-europe-migrants-germany-refugees-idUSKCN0V80IH
} 
correct that imbalance. As the above statements made by the German Chancellor imply, there is a pressing need, including from the perspective of policy design, to understand what prompts migrants to return to their countries of origin. From time to time, and for a variety of reasons, other countries that host migrants may also want them to leave. If policy formation in this sphere aligns with underlying motives for return, the need to resort to costly inducements to encourage migrants to depart could be less, and repatriation would be more effective. In November 2017, it was announced that the Israeli government would pay migrants from Eritrea and Sudan (whom it considers illegal migrants) USD 3,500 each for leaving the country voluntarily (https://www.haaretz.com/israel-news/1.823734). The decision to embark on this policy was not preceded by a study of the reasons for return migration. If, as an example and as shown below, the reason for undertaking migration is to reach a well-defined target, and if the reason for return migration is that the target has been reached, then understanding the nature of the target and fine-tuning the policy measures will be better than operating independently of aligning with the target.

This paper presents and explains 12 reasons for return migration. The reasons listed are derived from research on migration conducted by the author in the course of the past three and a half decades. As such, the list is not intended to be, and cannot possibly be, exhaustive; it is confined to ideas that were revealed and articulated in the course of that research. (When it comes to motives for any type of economic behavior, a list can hardly ever be finite.) Nor are the reasons provided mutually exclusive; the likelihood that a specific return event is motivated by a combination of reasons is presumed to be higher than the likelihood of it being motivated by a single reason. The order in which the reasons are presented is not hierarchical; because the motives for return are context-specific, they cannot be ranked. The purpose of this paper is to pull together insights gained in past research so as to formulate a base for and motivate future analytical, empirical, and policy-related inquiry. In addition, just as research on motives for migration can nourish a desire to establish the reasons for return migration, research on the latter can help deepen understanding of the former. In short, the material presented in this paper both summarizes a research program and lays out a research agenda.

The reasons discussed in this paper are essentially the result of microeconomic analysis. Clearly, the return of migrants to their places of origin can be for reasons that have nothing to do with their preferences or desires, or as a consequence of a particular type of behavior. For example, a change of regime in Thailand in May 2014 led to the deportation of illegal Cambodian 
migrants and to the consequent flight of others because they feared that the Thai military government would shoot unauthorized workers.

The reasons presented in this paper are titled as follows:

- Purchasing power;

- Strategic accumulation of human capital;

- Occupational status and social prestige;

- Asymmetric information;

- Social comparisons: ordinal preferences;

- Relative deprivation: cardinal preferences;

- Matching in the marriage market, and divorce;

- Receipt of inheritance;

- Meeting a target;

- Shocks at home;

- Costly separation caused by migration;

- Failure.

Each of these reasons is discussed in the next section.

\section{Reasons for return migration}

\section{Purchasing power}

The idea that a difference in the purchasing power of money between places of origin and destination can give rise to return migration was originally modeled in Stark et al. (1997). A rudimentary framework can capture the spirit of that model in a straightforward way.

Suppose that an individual chooses freely between two locations where he can live and work - in the destination (city) or in the place of origin (village) and that early in life he prefers to migrate to the city than to stay in the village. The observation that quite often the duration of labor migration is shorter than the individual's working life implies city-to-village migration. To see this, we sketch in Appendix A a model of return migration that is not associated with reversal of the wage differential between the places of destination and origin.

As shown in Appendix A, an increase in purchasing power in the home village, and a rise in wages in the city shorten the period of migration. Conventional migration models might have led us to expect that higher wages at destination would increase the relative attraction of the destination, presumably prolonging the stay there. Because life is finite and savings confer higher satisfaction in the home village than in the city when spending them in the home village buys more, return migration is attractive. As regards the response to a rise in wages in the city, our model suggests the converse. 
An interesting implication of the model is the possibility that a migrant might return home even though the wages there are zero. Once again, the reasoning is that the consequent possibility to save more in the city when wages there increase, results in spending time in the home village having greater appeal because it allows for drawing on savings there to improve consumption.

\section{Strategic accumulation of human capital}

Røed and Stark (1998) develop a model in which work abroad enhances skills for work at home in a manner that work at home cannot. The very purpose of migration is to lift the earning prospects at home. (Røed and Stark construct a wage function that relates positively the earning possibilities at home to the number of periods spent working abroad.) While living at home, as such, confers utility that living abroad does not, skill enhancement abroad, leading to a higher wage at home, can encourage migration even if the wage differential between abroad and home is negligible or negative, and can attract return migration even if the wage differential between abroad and home is positive. The combination of acquisition abroad of skills valuable in the home country and the preference for living at home compels a migrant to weigh the acquisition of additional skills and the associated extended stay abroad against a longer spell at home during which the higher wage can be enjoyed at home. Even when the wages awaiting him at home continue to increase while he is abroad, a migrant may prefer to return home earlier. Røed and Stark cite evidence of migration from and within Scandinavia, which reveals that nearly $80 \%$ of Danes and Norwegians who moved from their country of origin in 1981 returned within nine years. For Sweden, the corresponding percentage was between $50 \%$ and $60 \%$.

\section{Occupational status and social prestige}

Fan and Stark (2011) develop a theory of migration as a response to occupational stigma. Migration of this nature is usually by unskilled workers who are reluctant to perform degrading work at home, yet do not mind doing the very same work away from home. However, migration could also be undertaken in pursuit of occupational status by skilled workers. Many nationals from a number of developing countries such as India and China in recent times and Israel, Japan, and Korea in the 1960s and 1970s, who obtained their PhDs in the USA, returned home. While these individuals could have commanded good salaries in the USA, they nonetheless went back to receive considerably lower salaries at home. Drawing, with some modification, on the model developed by Fan and Stark, we can shed light on this phenomenon of return migration from a new angle. Fan and Stark 
assume that individuals derive utility from two sources: income and occupational status. Fan and Stark contend that an individual with a prestigious occupation - say, a university professor - enjoys occupational status. Moreover, the shorter the social distance between that individual and the people in his living environment, the higher his utility from occupational status. The esteem that the individual experiences is closely related to the social group to which he belongs, and to the psychological distance between himself and that group. In the USA, the social distance between, for example, an individual with a $\mathrm{PhD}$ who comes from Korea and the community he lives in is usually large. Consequently, he derives little status (utility) from being, say, a professor in the USA. In Korea, however, the social distance between himself and his community is short. People in his social group (family members, old classmates, and so on) bask in his glory. This is valuable to him; namely, he derives considerable utility from being a professor in his home country. Thus, individuals may choose to migrate back to their home country in order to draw away from a social group that is a large social distance from them and immerse themselves in a social group that is a small social distance from them. The model developed by Fan and Stark therefore implies that the migration of skilled workers can also be related to a desire for occupational status and social distance. This line of reasoning suggests a novel explanation for return migration from rich to poor countries.

If a migrant comes from a low-status family and if status at the place of origin matters to the migrant and his family, remittances can be utilized as a status-elevating device. This consideration could affect both the disposition and distribution of remittances. To the extent that elevated status hinges on a visible signal, a new house, for example, could well fit the bill. One reason why migrants' remittances are so often channeled into improved housing is that a superior house is an unequivocally visible measure, or statement, of status-yielding success, suggesting that the incentive to migrate in the first place was to acquire higher status. Once a house is built, the need for remittances declines, the rationale for migration weakens, and return may occur.

\section{Asymmetric information}

Information is rarely symmetric: when meeting to conduct a transaction, agents do not know all the characteristics of fellow agents that affect the outcome of the transaction, and often they know even less about the characteristics of fellow agents when the latter come from abroad, from a different culture. In particular, employers at the place of destination have less information about the individual skill level of migrant workers than both employers at the place of origin and the workers themselves. These observations invite us to address 
the role of informational asymmetry in return migration. Here we show informally how, in the context of the labor market, asymmetric information can lead to return migration and actually cause additional dynamics in migration behavior. A formal analysis is presented in Stark (1995).

In the context of an employment relationship, asymmetric information applies to the skill level of (new) employees. When information about the individual skill levels of migrant workers is unknown to employers at the place of destination, all migrant workers receive a wage based on the average product of the group of migrants. This wage formation procedure encourages low-skill workers who, without this averaging, would have stayed behind to move together with high-skill workers. When informational symmetry is restored through monitoring and observation, and wages are adjusted accordingly, the low-skill workers return to their place of origin. The high-skill workers stay, and their wages rise. Because now the individually identified (high-skill) stayers and (low-skill) returnees are removed from the pooling process, migration as above is replicated by a yet higher-skilled subset of workers. By migrating, workers constituting the first wave of migration block the migration of workers constituting a higher-skilled wave: the low average wage paid to the workers who constitute the first wave deters migration by higher-skilled workers whose wage at home matches their true skill level, but whose wage at the place of destination would be penalized by being averaged down. And by subsequently exposing themselves to identification, the first-wave workers pave the way for the migration of higher-skilled workers. Thus, migration proceeds in waves, with each wave dividing into workers who stay as migrants and workers who return, and within each wave the returning migrants are the low-skilled workers.

Two examples further illustrate the interaction between the state of information and the incidence and pattern of return migration. Suppose, first, that workers can have one of two skill levels - low and high. The model presented in Stark (1995) offers the following predictions: migration is ex-post fully positively selective even though to begin with it is not; migration splits into workers who stay at the place of destination and workers who return; and the returning workers are low skilled. Suppose, next, that workers in a profession can have one of several skill levels rather than just one of two skill levels. A plausible implementation of the model of labor migration under asymmetric information generates the following predictions: migration is sequential (phased); and not all workers who end up as migrants move at the same time. Each wave of migration (of migrants) breaks down into workers who stay as migrants, and workers who return. Ravenstein's century-old "law of migration" (1885, p. 199), stating that "each main current of migration produces a compensating counter-current" - often 
quoted but not generated analytically - turns out to be a derivative or a variant of the asymmetric information approach to migration. Within waves, the returning migrants are the low-skilled workers; thus, migration is ex-post positively selective within waves. When the migration process is completed, migration is mildly positively selective - the average skill of migrants is superior to the average skill of workers found at the place of origin - but not all migrants are of higher skill than all workers at the place of origin. (Only in the case of two types of workers does migration turn out to be ex-post fully positively selective.) Wave by wave, the average skill level of migrants rises. And wave by wave, the skill level of the returning migrants also rises.

\section{Social comparisons: ordinal preferences}

Here we highlight the role of distaste for falling behind others in the income hierarchy in driving migration and return migration.

How important is the desire for rank in explaining behavior? Brown et al. (2008), who study the relationship between pay and well-being, find that the wage rank of workers has a significant influence on the satisfaction that they derive from their wage payments. Powdthavee (2009) even finds that an individual's position in the wealth hierarchy within his local community affects his perceived economic well-being more than a comparison of his income with the mean income of the community. Boyce et al. (2010) argue that individuals gain utility (general life satisfaction) mainly from the rank (or position) of their income within a comparison group rather than from their absolute income per se. Indeed, writings both in economics and in sociology have long maintained that individuals have a strong preference for high (social) rank and are stressed when they have a low (social) rank. Smith has remarked that "the desire of ... obtaining rank among our equals, is, perhaps, the strongest of all our desires" (Smith, 1759, Part VI, Section I, Paragraph 4). Veblen (1899) has shown that other people's higher pay can depress one's utility. Maslow (1943) views status as a basic human need, and Huberman et al. (2004, p. 103) infer from a study of five societies that "subjects valued status independently of any monetary consequence." There is considerable evidence from research in modern economics to the effect that the desire to avoid low rank motivates workers to exert more effort (Neckermann \& Frey, 2008; Kuhnen \& Tymula, 2009; Duffy \& Kornienko, 2010; Kosfeld \& Neckermann, 2011), and students to perform better (Bandiera et al. 2009; Azmat \& Iriberri, 2010). Contemporary evidence nicely supports Smith's assessment of the power of the incentive to escape low rank as distinct from the desire for the tangible benefits associated with high rank. We demonstrate the role of distaste for falling behind others in 
the income hierarchy in prompting migration and return migration with the help of an example. In the spirit of Smith (1759), we distinguish between absolute income (which we hold constant) and ordinal rank.

Let there be a population of $n$ individuals, where $n$ is a natural number. To ease representation, we assume that the income of individual $i$ is $i, i=1,2, \ldots, n$; namely, the individual's income is the individual's name. However, everything that follows goes through if instead we have $\left(x_{1}, x_{2}, \ldots, x_{n}\right)$ as an ordered vector of incomes of a given population of $n$ individuals, namely when $x_{i}$ is the income of the individual $i$, and $x_{1}<x_{2}<\ldots<x_{n}$.

To begin with, all the individuals are in region A. Let (empty) region $\mathrm{B}$ come into being or become accessible such that migration between the two regions is possible, and is cost free. In all relevant respects, the two regions are identical. This implies that there is no reason arising from a difference in the regions' attractiveness for an individual to prefer to locate in one region as opposed to another. The reason for migration is that an individual wants to be in the region that better aligns with his social preferences, which are for a higher rank in the income hierarchy. When in terms of the outcome of social comparisons the regions are equally attractive (a tie), an individual does not migrate. Once an individual is in a region, the region becomes instantly his exclusive sphere of comparison. However, an individual can relocate as many times as he wishes, at no cost to himself, in response to the actual distribution of the individuals between the two regions. Put differently, an individual bases his decision to migrate on the observed current state, without forming expectations as to how other individuals will behave simultaneously. For ease of exposition, we refer to the steps of the dynamics of migration as periods, with the initial period being referred to as zero.

In period 0 , the $n$ individuals are in region A. In this case, in period 1, we will have the following distribution of the population (individual $n$ does not have an incentive to migrate, whereas all the other individuals move so as to gain a higher rank in region $\mathrm{B}$ ):

\begin{tabular}{|c|c|}
\hline $\mathrm{A}$ & $\mathrm{B}$ \\
\hline \multirow{2}{*}{$n$} & \\
& $n-1$ \\
& $n-2$ \\
& $n-3$ \\
& $n-4$ \\
& $\vdots$ \\
& 1 \\
\hline
\end{tabular}

But now each of the individuals $n-3, n-4, \ldots, 1$ can obtain a higher rank (second) if he were to move back to region A. Thus, individuals $n-3$, 
$n-4, \ldots, 1$ move to region $\mathrm{A}$, and in period 2 the distribution of the individuals will be:

\begin{tabular}{|c|c|}
\hline $\mathrm{A}$ & $\mathrm{B}$ \\
\hline$n$ & \\
& $n-1$ \\
& $n-2$ \\
$n-3$ & \\
$n-4$ & \\
$n-5$ & \\
$\vdots$ & \\
1 & \\
\hline
\end{tabular}

Once again, several individuals from region A (specifically, individuals $n-5$, $n-6, \ldots, 1)$ will have an incentive to move to region $\mathrm{B}$. We see that by period $\frac{n}{2}$ if $n$ is even or by period $\frac{n-1}{2}$ if $n$ is odd, all comings and goings will come to halt, and we will have the following steady-state distribution of the population:

\begin{tabular}{|c|c|}
\hline $\mathrm{A}$ & $\mathrm{B}$ \\
\hline$n$ & $n-1$ \\
& $n-2$ \\
$n-3$ & \\
$n-4$ & $n-5$ \\
& $n-6$ \\
$n-7$ & \\
$n-8$ & $n-9$ \\
& $\vdots$ \\
\hline
\end{tabular}

such that what remains to be characterized is the location of the two lowestincome individuals; namely, the location of individuals 1 and 2. It turns out that the whereabouts of these two individuals depends on whether $n$ is even or odd, and on whether when $n$ is even whether $n$ or $n-2$ is a multiple of 4 , and when $n$ is odd whether $n-1$ or $n-3$ is a multiple of 4 . Specifically, we have the following characterization. When $n$ is even, 1 and 2 are in different regions: if $n$ is a multiple of 4 , then 1 is in region $A$, and 2 is in region $\mathrm{B}$; if $n-2$ is a multiple of 4 , then 2 is in region $\mathrm{A}$, and 1 is in region $\mathrm{B}$. And when $n$ is odd, then 1 and 2 are in the same region: if $n-1$ is a multiple of 4 , then 1 and 2 are in region $A$; if $n-3$ is a multiple of 4 , then 1 and 2 are in region $\mathrm{B}$. 
In this example, there is a series of return migrations prompted by a desire for higher rank. In each period until the steady state is reached, the migration of individuals with relatively high incomes inflicts a negative externality on individuals with relatively low incomes. To correct for that, the latter individuals migrate back.

\section{Relative deprivation: cardinal preferences}

Considerable empirical evidence finds that relative deprivation is a statistically significant explanatory variable of migration behavior. Stark and Taylor (1991) show that relative deprivation increases the probability that household members will migrate from rural Mexico to the USA. More recently, Quinn (2006) reports that relative deprivation is a significant motivating factor in domestic migration decisions in Mexico. Stark et al. (2009) explore the relationship between aggregate relative poverty, which is functionally related to aggregate relative deprivation, and migration. Drawing on Polish regional data, they demonstrate that migration from a region is positively correlated with the aggregate relative poverty in the region. Czaika (2011) finds that in India, relative deprivation is an important factor in deciding whether a household member should migrate, especially in the case of migration over a short distance. Basarir (2012) reports that people in Indonesia are willing to bear a loss of absolute wealth if there is a relative wealth gain from migration. Jagger et al. (2012) demonstrate that relative deprivation is a significant explanatory variable of circular migration in Uganda. Drawing on data from the 2000 USA census, Flippen (2013) shows that both blacks and whites who migrate from the north to the south generally have lower average absolute incomes than their stationary northern peers, yet in the wake of their migration, they enjoy significantly lower relative deprivation. Vernazza (2013) finds that, even though interstate migration in the USA confers substantial increases in absolute income, the trigger for migration is relative deprivation (low relative income), not low absolute income. Hyll and Schneider (2014) use a data set collected in the German Democratic Republic in 1990 to show that aversion to relative deprivation enhanced the propensity to migrate to western Germany. The very same motives that underlie migration in these studies can just as well underlie return migration, as demonstrated both in this section and in the preceding section.

We illustrate how sensing relative deprivation can prompt return migration with the help of a sharp example. Here we measure relative deprivation in a cardinal way. Use of such a measure differentiates the approach taken here from the approach taken in the preceding section where rank (an ordinal measure) was used. This difference is intentional, because it adds robustness: there are several ways in which falling behind others can be calculated, and in the preceding and current sections we incorporate two of these ways. 
An individual whose income $x$ is in region $\mathrm{B}$, where the income of every other individual is also $x$. The individual can, alternatively, migrate to region $\mathrm{A}$ where the income awaiting him will be $z>x$, and where the income of the only other individual is also $z$. As assumed in the preceding section, the region where an individual is located constitutes the individual's sphere of social comparison. The individual likes absolute income and dislikes relative deprivation and assigns to these two terms in his utility function positive weights that sum up to one. Because the income in region $\mathrm{A}$ is higher than the income in region $\mathrm{B}$ and because no relative deprivation is experienced in region $\mathrm{A}$, the individual will migrate from region $\mathrm{B}$ to region $\mathrm{A}$. Let us assume now that the income of the other individual in region $\mathrm{A}$ increases from $z$ to a higher income, while the income of the individual who migrated from region $\mathrm{B}$ to region $\mathrm{A}$ remains unchanged at $z$. Now, this latter individual senses relative deprivation in region $\mathrm{A}$, which negatively affects his utility from staying in that region. It follows that if the individual's utility in region $\mathrm{A}$ is now lower than his utility in region $\mathrm{B}$, the individual will prefer to migrate back to region $\mathrm{B}$, even though this migration results in him having a lower income. The intuition is that if the weight that the individual assigns to relative deprivation is higher than a critical level, then low income with no relative deprivation is worth more to him than high income combined with relative deprivation. A formal representation of the reasoning in this subsection is presented in Appendix B.

\section{Matching in the marriage market, and divorce}

Men may migrate to accumulate wealth that will improve their prospects in the marriage market. Single men assign a higher value to social status than do single women (Huberman et al., 2004), taking the importance attached to low relative wealth as a measure of the importance attached to low status. This difference by gender can be explained by the fact that low status carries a harsher penalty for single men than for single women, which, in turn, arises from the fact that low status for single men translates into inferior outcomes in the marriage market: in selecting a partner, the social status of a man is more important to a woman than the social status of a woman is to a man (Kenrick et al., 1990).

To understand why status matters to men more than it does to women, we invoke evolutionary, socio-biological reasoning, attributing gender-specific behaviors to different selective pressures faced by females and males. ${ }^{2}$ Male

2 The typical reference in the evolutionary literature is to males and females, not to men and women, so in this paragraph we keep in line with this convention. 
fitness is limited by access to fecund females, whereas female fitness is limited by physiological and energy constraints. Successful males can enhance their fitness by monopolizing the reproductive performance of several females, whereas the fitness of females cannot profit from multiple mates to the same extent. Females are, therefore, a 'contested resource' for which males compete. ${ }^{3}$ This competition need not take the form of a direct contest for females. Instead, males compete for assets ranging from feeding territories and food to more intangible 'resources' like social status, which can be converted into a reproductive opportunity, whether because they are directly attractive to females or because they help defeat rival males. In short, status is a means of gaining a valuable resource via a better hierarchical position, and evolution has embedded this concern for status into individual preferences.

The received literature has long correlated high status with superior outcomes in the marriage market, and social status with relative wealth. We refer briefly to a number of studies that have modeled these links. With regard to status and the marriage market, Becker (1973) provides a theoretical foundation for the importance of status in the maximization of matching quality in the marriage market. Cole et al. (1992) develop a model in which "men and women who will match have preferences over the matches they will enter into. ... Relative success in the matching process will be determined by agents' status" (p. 1097). Cole et al. note that men differ in their wealth, and that women are characterized by varying degrees of quality, which, in turn, constitutes an argument in men's utility function. The model of Cole et al. suggests that, in equilibrium, women of higher quality choose richer men. This choice or preference intensifies men's distaste for having low relative wealth. Robson (1996) remarks: "Males obtain more offspring as a consequence of greater wealth both directly and because this attracts more mates. The second effect induces gambling driven by relative wealth ..." (p. 190).

With regard to the conversion of relative wealth into (social) status, a natural starting point is Smith (1759), where we read that wealth accumulation yields social status and that status matters for individual welfare. Veblen (1899) dwells at length on the notion that in modern Western societies the aspiration for high relative wealth is motivated by an underlying desire for social status. In his study of the origins of modern English society, Perkin $(1969$, p. 85$)$ comments that "the pursuit of wealth was the pursuit of social 
status." Frank (1985) emphasizes the significance of relative wealth for the acquisition of social status. Robson (1992) develops a model of decision-making in which agents care not only about their wealth, but also about their relative position in the wealth distribution. Robson (p. 837) writes: "[O]rdinal rank in the wealth distribution enters von NeumannMorgenstern utility as an argument in addition to wealth itself. Thus, higher wealth increases utility not only directly but also indirectly via higher status." Futagami and Shibata (1998, p. 110) define a "person's relative wealth position in the society [as] status." Pham (2005, p. 407) develops a model in which social status is "increasing with individual wealth and decreasing with the average wealth of the society."

When men migrate in order to improve their wealth rank at the place of origin and marry better at home, their migration and return migration are components of a single strategy. For example, there is indirect evidence (Drinkwater et al., 2009; UK Office for National Statistics, 2015) supporting the notion that Polish single men migrate to the UK temporarily to accumulate wealth in order strategically to improve their position (value) in the marriage market in Poland.

Under a variety of circumstances, divorce will propel migration and return migration, and not only to reduce the psychological costs associated with dissolution ('to start a new life') or to avoid making child-support payments. Often, location decisions are made jointly by the married couple so as to maximize joint wage income. If the inter-market variation in men's wages is larger than the inter-market variation in women's wages, and if women's wages are not strongly positively correlated with those of men, then when it comes to the choice of location, the husband's wage will weigh more heavily than the wife's wage in the couple's decision of where to locate in order to maximize their joint earnings. The terminology often used to describe this situation is that the wife is a tied migrant. Suppose, then, that a married couple migrated with the wife's wage at the place of destination being lower than her wage at the place of origin. Consequently, during the marriage, the labor market location of the husband aligns with his earning ability better than the labor market location of his wife aligns with her earning ability. In the event of divorce, the husband would be less likely to have a wage-based motivation to migrate back than the wife who, under these assumptions, has sacrificed her own wage prospects during her marriage. All other things being the same, under these circumstances of divorce, higher return migration rates by women than by men will be observed. To some extent, this prediction is confirmed by evidence presented three decades ago by Sander (1985); in the USA in 1970, farm 
and rural non-farm divorced women migrated more frequently than farm and rural non-farm divorced men.

\section{Receipt of inheritance}

A nice way to link migration, return migration, and inheritance is via remittances. In its choice of who migrates, a family may be affected by the prevailing rules of inheritance. Consider a setting in which inheritance is governed by primogeniture - the exclusive right of the eldest son to the family's farm (Stark, 1999). As migrants, second and later children will not be motivated to remit by an aspiration to inherit. In contrast, as a migrant, the eldest son will be encouraged to remit if he knows that his transfers will be invested in the family's farm, and these transfers, in turn, will serve to boost the value of his inheritance. Once the son actually inherits the farm, he will have an incentive to return.

The institution of primogeniture can be linked with return migration in other ways too. As migrants, second and later children who do not expect to inherit will be motivated to boost their earnings by acquiring human capital as an alternative to the 'land capital' (the family's farm) that the eldest son will receive. To the extent that the acquired human capital is location specific, the opportunity cost of second and later children of returning home at the time of inheritance will be high, even if in the course of their lifetime the regime of primogeniture was replaced by equality of inheritance. Moreover, to the extent that investment in human capital bears fruit in the form of good returns on its gains away from home, return migration by those who acquired human capital will be less likely than by those who did not. Thus, in situations in which the eldest son as well as other children migrated, the likelihood of return migration by the eldest son will be higher.

\section{Meeting a target}

Suppose that the original aim of migration (and possibly of remitting) is to achieve a specific investment objective in the home village - say, setting the migrant's parents up as shopkeepers in order to secure for them a steady stream of income in the future, or to install a tube well, or to acquire a truck in order to take produce grown in the village to the nearby town. The reason for migration to the city or beyond is to acquire a specific physical capital. Once the acquisition is made and the objective is met, the migrant will return. Similar reasoning applies to paying for advanced schooling (college education) for children. Migrants from the Philippines told the author that they would end 
their work in a rich Gulf state and return home once their children graduated from college. ${ }^{4}$

\section{Shocks at home}

One reason for a migrant's return is a severe adverse shock to the livelihood of his household back home. Even if continued work at the migration destination and the consequent transfer of remittances would help a stricken household, migrants and their households may consider it beneficial at a time of extreme misfortune (for example, a hurricane or an earthquake) for the migrant to return. The support that the migrant can provide to the household by his actual presence (for instance, when labor to repair serious damage cannot be hired locally) may exceed the benefits from transferring remittances. This could explain the seemingly paradoxical return migration to El Salvador in the wake of the devastating earthquake of 2001 (Halliday, 2006).

There are countries and regions that are prone to severe shocks: for example, flooding in Bangladesh during the monsoon season is a frequent occurrence. There are a variety of ways in which people can and do prepare to protect themselves from the effects of natural disasters, and one of them is obtaining on-site help from the migrant's family members. It appears that when natural disasters are mild, remittances serve as a relief; when the disasters are severe, return migration is the chosen response. This consideration yields yet another testable proposition related to the incidence and pattern of return migration.

4 It is interesting to inquire how the identification of migrants as target migrants can inform public policy. Last year, an idea was raised with the author of this paper of taxing migrants in the Gulf region. How can taxation be implemented while preserving the incentives for migrants to come in the first place, or not to withdraw altogether? Suppose that migrants are target migrants: they seek to accumulate $x$ income units and then they will return to their home country. Suppose also that in order to amass $x$ income units, they work $n$ years. Then the accumulation per year is $x / n$ income units. Now the host country imposes a yearly tax at the rate of $t, 0<t<1$. The amount saved in $n$ years will then be reduced to $x(1-t)$ income units. Suppose, however, that the host country allows the migrants to stay longer. If it extends their stay to $n /(1-t)$ years, then the migrants will end up with their target of $x$ income units. (An underlying requirement for the scheme to work is that the migrants do not experience substantial loss of utility from staying longer in the host country.) Thus, a concrete policy means would be, simultaneously with the imposition of the tax, to allow a corresponding / matching prolongation of the duration of the migrants' work permit. Migrants will still come, and they will still migrate back, with the duration of the postponement of their return being an increasing function of the tax rate. 


\section{Costly separation caused by migration}

There is a form of migration where return migration is built in as a regular and repetitive feature. Under certain conditions, this form is preferable to alternative forms of migration.

Consider a family with one breadwinner, whom, in line with the 'New Economics of Labor Migration' (Stark, 1993), we view as an agent who migrates on behalf of his family in order to maximize the well-being of the family. Suppose that the breadwinner has three migration options available to him: a sequence of episodes of seasonal migration; permanent migration by himself; and permanent migration together with his family. In comparison with the second and third options, an advantage of the first option can arise from the conjunction of two factors: the cost of separation from home, and the cost of living abroad. When the latter cost is relatively high (when it is expensive for the entire family to live abroad), migrating alone has an edge; it facilitates earning money in the host country and spending it in the home country (recall the subsection entitled 'Purchasing power'). A drawback, however, of migrating alone is the suffering caused by separation from one's family. This drawback is particularly burdensome when it becomes increasingly difficult for the breadwinner and his family to sustain separation as its duration lengthens. In essence, the cost of separation is the sum of two costs: that which is caused by the breadwinner's suffering as a result of separation from his family, and that which is caused by the family's suffering as a result of separation from the breadwinner; an altruistic breadwinner takes into account the cost imposed by his absence on the members of his family who stay behind.

Kepinska and Stark (2013) documented the durability of seasonal migration from Poland to Germany, a phenomenon that has persisted for more than a century. They refer to the role of the tradition of engaging in seasonal migration as a force that helped invigorate the process and contributed to its sustainability even when, to different degrees and at different times, the process was interrupted by a shifting political, regulatory, and legal environment. (Evidence in support of the role of tradition is provided, among other things, by the continuation of the seasonal flow of migrants from once-border regions - which became internal regions following World War II - despite the fact that since the redrawing of the GermanPolish border, proximity is no longer a factor encouraging repeated, short-term seasonal moves.) Stark and Fan (2007) sought to provide a rationale for the observed durability of this very phenomenon. They showed analytically how the cost of living differential and the cost of separation shape seasonal migration outcomes to a significant degree and, in particular, 
how balancing of the two costs invites a series of seasonal migrations, each of a relatively short duration. Placed in the context of the current paper, the ability to return constitutes a necessary condition for migration. Consequent testable predictions are then, other things being equal, that: heads of families with young children for whom the cost of separation will be high will be more inclined than other heads of families to opt for seasonal migration / be correspondingly more present in the group of return migrants; a narrowing of the difference in the cost of living between abroad and home will encourage substitution of permanent migration together with families for seasonal migration alone / result in a correspondingly reduced incidence of return migration; and so on.

\section{Failure}

Migrants will return to their place of origin when at the place of destination they fail to gain employment, they lose hope that their fortunes will turn around, or they are unable to sustain themselves any longer. Rough living is the mother of return.

Although 'the economics of return migration as a response to failure' has yet to be written, there are several ways in which behavior and choices can reduce the likelihood of return migration because of failure. One such way will be for the migrant's household to select as a migrant a member who will be strongly committed to search for gainful employment, say, and who will try hard to avoid failure. In the Philippines, this consideration has resulted in the choice of a daughter rather than a son as a family migrant, even when the earnings of male migrants are on average higher than the earnings of female migrants (Lauby \& Stark, 1988). A lower probability of return migration caused by failure even when combined with low expected earnings is preferable to the household as compared to a higher probability of failure-generated return migration combined with high expected earnings.

\section{Conclusion}

It can be assumed that the reasons for studying return migration are as many as the reasons for return migration itself. We have seen that the reasons for return migration are more involved than a simple dichotomy between success and failure, voluntary and imposed, planned and exogenously mandated, prevailing singly or jointly with others, and so on. Ravenstein's (1885) 'law of migration' that every migration flow produces a return flow is fine as it is, but it is of no use when we seek to understand why migrants return, how long after departing they do that, or who amongst a group of migrants is most 
likely to return. Modern applied microeconomics fills in where Ravenstein left off, provides insights, and formulates testable hypotheses.

Interest in the circumstances and conditions under which migrants return is obviously shared by policy-makers. For example, host countries in East and South East Asia such as South Korea, Singapore, and Malaysia have devised a plethora of measures aimed at seeing to it that migrants return to their home countries after a stay of an approved duration. If host countries could exploit the reasons presented in this paper to create profiles of migrants who are more likely to return of their own accord, as opposed to others who will not, then admitting the former will allow costly measures to monitor the duration of stay and enforce compliance to be scaled back.

Implications for new policy options can be drawn not only from the individual reasons for return listed above, but also from those reasons considered jointly. To illustrate this point, we consider the reasons discussed in the subsections entitled 'Social comparisons: ordinal preferences' and 'Relative deprivation: cardinal preferences.' Taken together, these reasons point to a new utility representation and to a corresponding policy regarding return migration. In addition to caring about their absolute income, let the individuals be concerned jointly and separately about their rank in the income distribution, and about the extent to which their income falls below the incomes of others in their comparison group. Consider five individuals whose incomes are (1, 2, 3, 4, 5). In this income distribution, the position of individual 3 (as in the 'Social comparisons: ordinal preferences' subsection, the individual's income is the individual's name) is third from the top, and his relative deprivation calculated, say, as the distance below the mean income of the richer individuals - is $4.5-3=1.5$. Suppose that individual 2 gets an increase in income to obtain income 4.5. The position of individual 3 falls (in the income distribution $(1,3,4,4.5,5)$ he is fourth from the top). There is no change in his income, and there is no change in the average income of the richer individuals. Nonetheless, there is a corresponding utility loss, which could prompt individual 3 to return home. Suppose, further, that the host country does not want that to happen. A policy response could be to address the change in individual 2's income: not to prevent individual 2 from gaining an income increase altogether, but rather to limit that increase to one unit of income, in which case the utility of individual 3 will remain intact.

An expansion of the utility function to incorporate absolute income and $a$ vector of social preferences containing an ordinal component and a cardinal component is very much at the frontier of research into migration, and also at the frontier of behavioral science research. 


\section{Acknowledgements}

I am indebted to a reviewer for helpful remarks, constructive advice, and kind words, and to Adam Oliver for guidance and caring editorial management.

\section{References}

Azmat, G. and N. Iriberri (2010) 'The importance of relative performance feedback information: Evidence from a natural experiment using high school students', Journal of Public Economics, 94(7-8): 435-452.

Bandiera, O., V. Larcinese and I. Rasul (2009) 'Blissful ignorance? Evidence from a natural experiment: On the effect of individual feedback on performance.' London School of Economics, Mimeo.

Basarir, H. (2012) 'Is it all relative? The role of wealth in the migration decision: Evidence from Indonesia.' Working paper, University of York.

Becker, G. S. (1973) 'A theory of marriage: Part I', Journal of Political Economy, 81(4): 813-846.

Boyce, C. J., G. D. A. Brown and S. C. Moore (2010) 'Money and happiness: Rank of income, not income, affects life satisfaction', Psychological Science, 21(4): 471-475.

Brown, G. D. A., J. Gardner, A. J. Oswald and J. Qian (2008) 'Does wage rank affect employees' well-being?' Industrial Relations, 47(3): 355-389.

Cole, H. L., G. J. Mailath and A. Postlewaite (1992) 'Social norms, savings behavior, and growth', Journal of Political Economy, 100(6): 1092-1125.

Czaika, M. (2011) 'Internal and international migration as response of double deprivation: Some evidence from India.' Proceedings of the German Development Economics Conference, Berlin 2011, No. 21.

Drinkwater, S., J. Eade and M. Garapich (2009) 'Poles apart? EU enlargement and the labour market outcomes of immigrants in the United Kingdom', International Migration, 47(1): 161-190.

Duffy, J. and T. Kornienko (2010) 'Does competition affect giving?' Journal of Economic Behavior and Organization, 74(1-2): 82-103.

Fan, C. S. and O. Stark (2011) 'A theory of migration as a response to occupational stigma', International Economic Review, 52(2): 549-571.

Flippen, C. (2013) 'Relative deprivation and internal migration in the United States: A comparison of black and white men', American Journal of Sociology, 118(5): 1161-1198.

Frank, R. H. (1985) Choosing the right pond: Human behavior and the quest for status. Oxford: Oxford University Press.

Futagami, K. and A. Shibata (1998) 'Keeping one step ahead of the Joneses: Status, the distribution of wealth, and long run growth', Journal of Economic Behavior and Organization, 36(1): $109-126$.

Halliday, T. (2006) 'Migration, risk, and liquidity constraints in El Salvador', Economic Development and Cultural Change, 54(4): 893-925.

Huberman, B. A., C. H. Loch and A. Önçüler (2004) 'Status as a valued resource', Social Psychology Quarterly, 67(1): 103-114.

Hyll, W. and L. Schneider (2014) 'Relative deprivation and migration preferences', Economic Letters, 122(2): 334-337.

Jagger, P., S. Gerald and A. Arinaitwe (2012) 'Circular migration, small-scale logging, and household livelihoods in Uganda', Population and Environment, 34(2): 235-256. 
Kenrick, D. T., E. K. Sadalla, G. Groth and M. R. Trost (1990) 'Evolution, traits, and the stages of human courtship: Qualifying the parental investment model', Journal of Personality, 58(1): 97-116.

Kepinska, E. and O. Stark (2013) 'The evolution and sustainability of seasonal migration from Poland to Germany: From the dusk of the 19th century to the dawn of the 21st century', International Review of Economics and Finance, 28: 3-18.

Kosfeld, M. and S. Neckermann (2011) 'Getting more work for nothing? Symbolic awards and worker performance', American Economic Journal: Microeconomics, 3(3): 86-99.

Kuhnen, C. and A. Tymula (2009) 'Rank expectations, feedback and social hierarchies.' Northwestern University, Mimeo.

Lauby, J. L. and O. Stark. (1988) 'Individual migration as a family strategy: Young women in the Philippines', Population Studies, 42(3): 473-486.

Maslow, A. H. (1943) 'A theory of human motivation', Psychological Review, 50(4): 370-396.

Neckermann, S. and B. S. Frey (2008) 'Awards as incentives.' University of Zurich, IEW Working Paper No. 335.

Perkin, H. J. (1969) The origins of modern English society, 1780-1880. London: Routledge and Kegan Paul.

Pham, T. K. C. (2005) 'Economic growth and status-seeking through personal wealth', European Journal of Political Economy, 21(2): 407-427.

Pongou, R. and R. Serrano (2013) 'Fidelity networks and long-run trends in HIV / AIDS gender gaps', American Economic Review, 103(3): 298-302.

Powdthavee, N. (2009) 'How important is rank to individual perception of economic hierarchy? A within-community analysis', Journal of Economic Inequity, 7: 225-248.

Quinn, M. A. (2006) 'Relative deprivation, wage differentials and Mexican migration', Review of Development Economics, 10(1): 135-153.

Ravenstein, E. G. (1885) 'The laws of migration', Journal of the Royal Statistical Society, 48: $167-227$.

Robson, A. J. (1992) 'Status, the distribution of wealth, private and social attitudes to risk', Econometrica, 60(4): 837-857.

Robson, A. J. (1996) 'The evolution of attitudes to risk: Lottery tickets and relative wealth', Games and Economic Behavior, 14(2): 190-207.

Røed, M. and O. Stark (1998) 'On the optimal duration of migration', in Y. Mundlak (ed.), Labour, food, and poverty. London: Macmillan.

Sander, W. (1985) 'Women, work and divorce', American Economic Review, 75: 519-523.

Smith, A. (1759) The theory of moral sentiments. London: A. Millar.

Stark, O. (1993) The migration of labor. Oxford and Cambridge, MA: Blackwell.

Stark, O. (1995) 'Return and dynamics: The path of labor migration when workers differ in their skills and information is asymmetric', Scandinavian Journal of Economics, 97(1): $55-71$.

Stark, O. (1999) Altruism and beyond: An economic analysis of transfers and exchanges within families and groups. Cambridge: Cambridge University Press.

Stark, O. (2013) 'Stressful integration', European Economic Review, 63: 1-9.

Stark, O. (2016) 'Global integration and world migration', World Economics, 17(4): 49-65.

Stark, O. and C. S. Fan (2007) 'The analytics of seasonal migration', Economics Letters, 94(2): 304-312.

Stark, O., C. Helmenstein and Y. Yegorov (1997) 'Migrants' savings, purchasing power parity, and the optimal duration of migration', International Tax and Public Finance, 4(3): 307-324.

Stark, O., M. Micevska and J. Mycielski (2009) 'Relative poverty as a determinant of migration: Evidence from Poland', Economics Letters, 103(3): 119-122. 
Stark, O. and E. J. Taylor (1991) 'Migration incentives, migration types: The role of relative deprivation', Economic Journal, 101: 1163-1178.

Stark, O. and Y. Q. Wang (2005) 'Towards a theory of self-segregation as a response to relative deprivation: Steady-state outcomes and social welfare', in L. Bruni and P. L. Porta (eds.), Economics and happiness: Framing the analysis. Oxford: Oxford University Press.

UK Office for National Statistics (2015) 'Parents' country of birth, England and Wales: 2014.' London.

Veblen, T. (1899) The theory of the leisure class. Reprints of Economic Classics, New York: Augustus M. Kelley, 1965 reprint.

Vernazza, D. (2013) 'Does absolute or relative income motivate migration?' London School of Economics, Mimeo.

\section{Appendix A: A model of return migration that is not associated with reversal of the wage differential between the places of destination and origin}

We make the following assumptions:

1. Consumption per time period is fixed at a constant baseline consumption level; that is, the income elasticity of consumption is equal to zero, and the level of consumption in the home village is equal to the level of consumption in the destination city, and this level of consumption is given by $C$.

2. The wage in the village upon return is zero. The wage in the city, $W_{F}$, is positive and is higher than consumption in the city.

3. The life expectancy of individuals is fixed at $T$.

4. The stay in the city, denoted by $t_{F} \leq T$, is continuous.

5. Purchasing power in the village is $E$ times higher than in the city. This implies that savings are $E$ times higher in value when transferred to the village than if retained for use in the city.

6. At the end of his life, the individual leaves zero net wealth; there are no bequests in the model.

7. For simplicity's sake, the rate of interest is assumed to be equal to zero.

8. All else being equal, a given level of consumption in the village is (marginally) more enjoyable than the same level of consumption in the city.

For a migrant in the city who considers returning to his home village, consumption in the village must be equal to $E$ times the savings generated from work in the city:

$$
\left(T-t_{F}\right) C=\left(W_{F}-C\right) t_{F} E .
$$

From this equation, the duration of stay in the city can be expressed as:

$$
t_{F}=\frac{T}{1+E\left(\frac{W_{F}}{C}-1\right)} .
$$


Other things being constant, this equation yields the result that $t_{F}$ is inversely related both to $E$ and to $W_{F}$ : an increase in purchasing power in the home village and a rise in wages in the city shorten the period of migration.

\section{Appendix B: A model of return migration that is prompted by experiencing relative deprivation}

Here we build on an example presented in Stark (2016). An individual whose income is $y-2$, where $y>2$, is in region $\mathrm{B}$, where the income of every other individual is also $y-2$. The individual can, alternatively, migrate to region A, where the income awaiting him will be $y$, and where the income of the only other individual is also $y$. As assumed in the subsection entitled 'Social comparisons: ordinal preferences,' the region where an individual is located constitutes the individual's sphere of social comparison. The individual likes absolute income and dislikes relative deprivation (which we measure by the aggregate of income excesses divided by the size of the population as, for example, in Stark, 2013) and assigns to these two terms in his utility function the weights of $\alpha$ and $(1-\alpha)$, respectively, where $\alpha \in(0,1)$. (Formally, the individual's utility function can be represented by $u(x, R D)=\alpha x-(1-\alpha) R D_{k}$, where $x$ denotes the individual's income, and $R D_{k}$ denotes his relative deprivation while in region $k=A, B$.) Because $\alpha y>\alpha(y-2)$ and $R D_{A}=R D_{B}=0$, the individual will indeed migrate from region $B$ to region $A$. (In order to concentrate on essentials, we assume a zero cost of migration.) Assume now that the income of the other individual in region $\mathrm{A}$ increases from $y$ to $3 y$, while the income of the individual who migrated from region $\mathrm{B}$ to region $\mathrm{A}$ remains unchanged at $y$. Now, this latter individual senses in region A relative deprivation at the level of $(1 / 2)(3 y-y)$, which negatively affects his utility from staying in region A with the weight $(1-\alpha)$. It follows that if the individual's utility in region $\mathrm{A}$ is lower than his utility in region $\mathrm{B}$, namely if $\alpha y-(1-\alpha)(1 / 2)(3 y-y)<\alpha(y-2)$, which, on simplification, reduces to $\alpha<\frac{y}{y+2}$, then the individual will prefer to migrate back to region $\mathrm{B}$, even though this migration entails receiving a lower income $(y-2<y)$. The intuition underlying the condition $\alpha<\frac{y}{y+2}$ is that if the weight that the individual assigns to income, $\alpha$, is lower than some critical value $\frac{y}{y+2}$, which is the same as if the weight that the individual assigns to relative deprivation, $(1-\alpha)$, is higher than some critical value $\frac{2}{y+2}$, 
then low income with no relative deprivation is worth more to him than high income combined with relative deprivation.

This result is robust if submitted to an alternative way of measuring relative deprivation. Suppose that instead of calculating $R D$ as the sum of the income excesses divided by the size of the population, it is measured as $\max \{\bar{x}-x, 0\}$; namely, as the distance below the mean. When the incomes in region $\mathrm{A}$ are as above, namely $y$ and $3 y$, the mean income in region $\mathrm{A}$ is $2 y$, and the income distance of the individual in region A whose income is $y$ from this mean income is $y$. This yields $\frac{3 y+y}{2}-y$ as $R D$ in region $\mathrm{A}$, which is the same as $(1 / 2)(3 y-y)$ and thus leads to the same conclusion as above. $^{5}$

5 Methodologically, the modeling in this appendix is distinct from the modeling in Stark and Wang (2005), where migration and return migration were analyzed under the assumption that incomes are held constant, so that comparisons between bundles of high income / high relative deprivation and bundles of low income / low relative deprivation could not be performed. 